\title{
A LEITURA NA FORMAÇÃO INICIAL DO PROFESSOR: O FORMADOR EM CENA
}

\section{THE READING ON INITIAL TEACHER TRAINING: THE TRAINER ON THE SCENE}

\author{
Sandro Luís da Silva (UNINOVE/SP) \\ Cirlei Izabel da Silva Paiva (PUC/SP) \\ Cabe a cada indivíduo e a cada \\ geração perceber-se dentro do seu \\ mundo já construído e reconstruí-lo e \\ resignificá-lo. A Educação é parte da \\ construção coletiva do mundo. (Alípio \\ Casari)
}

Resumo: O objetivo deste texto é relatar uma pesquisa sobre o trabalho com leitura na formação inicial do professor de língua portuguesa. Adotou-se uma abordagem qualitativa na busca de informações junto a três informantes de curso de Letras de três Instituições de Ensino Superior - IES do Estado de São Paulo. O estudo baseou-se, sobretudo, em Veiga (1998), Pimenta e Anastasiou (2002), Kaufman \& Rodriguez (1995), Solé (1998), Silva (2005), Schneuwly \& Dolz (2004); a LDBN (1996); as Propostas Curriculares do Curso de Letras; o Parecer 9/2001 do MEC; e o Projeto Pedagógico do Curso de cada uma das IES. Observou-se que o curso superior ainda apresenta defasagens em relação ao trabalho com a leitura, havendo necessidade de se pensar em estratégias que tornem a leitura significativa para o futuro professor.

Palavras-chave: Leitura. Formação. Estratégia.

Abstract: The aim of this paper is a research report on working with in the initial reading of the Portuguese language teacher. We adopted a qualitative approach in seeking information from three informants Bachelor's IES three of São Paulo. The study was based mainly in Veiga (1998), Pepper and Anastasiou (2002), Kaufman \& Rodriguez (1995), Solé (1998), Silva (2005), Dolz \& Schneuwly (2004); the LDBN (1996); Proposals Curriculum Course Letters, Opinion 9 / 2001 of the MEC, and the Pedagogical Project of the course of each IES. It was observed that the college still has gaps in relation to work with reading, there is a need to rethink strategies that make reading meaningful for future teachers.

Key words: reading. Training. Strategy.

\section{Considerações Iniciais}

Tornou-se comum afirmar que as práticas pedagógicas encontram-se configuradas em dois eixos: o tradicional, realizado como prática pedagógica tradicional, dominante, repetitiva e o reflexivo, marcado por possibilidades de mudanças, com práticas reflexivas e construtivistas.

\begin{tabular}{|l|l|l|l|l|l|}
\hline Interfaces da Educ. & Paranaíba & v. 2 & n. 5 & p.46-57 & 2011 \\
\hline
\end{tabular}


Para a realização deste estudo, pactuamos com a ideia de que, para a formação inicial de um professor competente, na concepção de Perrenoud (1999), é preciso voltála para práticas reflexivas. Assim, partimos da necessidade de não só refletir sobre o processo de formação inicial do professor de língua portuguesa, mas, sobretudo, preocupar-nos com a melhoria dessa formação, uma vez que, segundo Lorieri et al (1996, p. 17), "é urgente construir saberes que apontem novos fazeres na formação de professores."

Segundo Veiga (1988), a prática pedagógica reflexiva pressupõe o vínculo indissolúvel entre teoria e prática, entre finalidade e ação, entre o saber e o fazer, ou seja, entre o que o professor pensa e o que ele faz. Ela exige, na verdade, uma acentuada presença da consciência crítica, ação recíproca entre professores, alunos e realidade.

Como informa o Parecer 9/2001 (p. 9),

a formação de professores como preparação profissional passa a ter papel crucial, no atual contexto, agora para possibilitar que possam experimentar, em seu próprio processo de aprendizagem, o desenvolvimento de competências necessárias para atuar nesse novo cenário, reconhecendo-a como parte de uma trajetória de formação permanente ao longo da vida.

Considerando que a leitura constitui-se em um processo cognitivo que busca, a partir do conhecimento prévio, uma (in)formação do aluno para que ele possa atuar no mundo em que está inserido, é necessário que o trabalho realizado pelos professores formadores leve o discente a uma reflexão "no que" e "no como" realizar na/a prática de leitura na sala de aula da escola básica, possibilitando-lhe a criação de estratégias para as futuras atividades de leitura que ele desenvolverá junto a seus alunos.

No mundo contemporaneo, o saber fragmentado vem dando lugar para uma nova concepção de conhecimento e de mundo. Assim, não cabe mais o modelo de escola estruturada no paradigma tradicional, cuja aprendizagem ocorre de forma mecânica, em que o saber é fragmentado, desconectado com o mundo vida, pronto e acabado, acrítico. Cada dia mais se exige uma nova postura frente ao conhecimento, uma postura inter e multidisciplinar. Dessa forma, é preciso ter uma atitude de pesquisa, de investigação, um olhar para o todo. O conhecimento escolar precisa estar em sintonia com os saberes necessários no mundo vida. É preciso estabelecer um dialógo contínuo entre o conhecimento científico e o senso comum, para que se perceba o significado do aprender na vida cotidiana. E assim há de ser a ação do professor formador na sala de aula, para que a ação seja refletida em seus alunos durante a prática docente no Ensino Fundamental e Médio.

No novo modelo de escola que se firma na contemporaneidade, não cabe a presença de um saber fragmentado, pronto e acabado, acrítico. Exige-se uma atitude de pesquisa, de investigação, de olhar inter ou multidisciplinar. E assim há de ser a ação do professor formador na sala de aula, para que a ação seja refletida em seus alunos durante a prática docente no Ensino Fundamental e Médio.

Não se concebe mais uma educação tecnicista e o ensino de leitura enquanto apenas decodificação de sinais gráficos. É preciso que a escola leve o aluno a entender, cada vez mais, a leitura como prática social.

Constata-se, assim, que um novo perfil de docente é exigido na escola, cujas palavras de ordem, segundo Pimentel (1993), são questionar, mudar, procurar, descobrir, inventar, modificar, sentir, participar, arriscar, inovar, a fim de que o espaço da sala de aula constitua-se em um lugar democrático, em que a reflexão seja um dos

\begin{tabular}{|l|l|l|l|l|l|}
\hline Interfaces da Educ. & Paranaíba & v. 2 & n. 5 & p.46-57 & 2011 \\
\hline
\end{tabular}


possíveis caminhos para a construção do conhecimento. Esta prática pedagógica reflexiva tem de começar na formação inicial do professor, a fim de desenvolver no futuro professor de língua portuguesa a competência de evidenciar a importância da leitura no dia a dia do cidadão. Um docente em sintonia com as novas descobertas da tecnologia, capaz de ser criativo e perceber que conhecimento não é posse e sim troca.

Procuramos com esta pesquisa a busca não de uma resposta, mas proporcionar uma reflexão sobre os caminhos percorridos pelo professor formador no exercício de suas atividades docentes em relação à prática da leitura no ensino superior, as quais precisam capacitar o futuro professor para atuar como cidadão crítico, agente transformador em interação com os seus pares durante o desenvolvimento da docência na escola básica.

\section{Referencial Teórico}

A partir dos trabalhos da Linguística Textual, os aspectos discursivos da linguagem passaram a fazer parte no processo de ensino-aprendizagem de língua portuguesa na escola. A linguagem torna-se objeto de ensino, porque se faz presente não só no espaço da sala de aula, mas no dia a dia das pessoas. É por meio dela que os indivíduos interagem com/no mundo. Tratar de linguagem constitui-se em uma tarefa complexa, já que pressupõe o monitoramento de aspectos lingüísticos, cognitivos e sociais. O desenvolvimento da habilidade de leitura no espaço escolar precisa levar em consideração esses três aspectos, pois a leitura é uma prática social, uma atividade de linguagem, em cujo processo se encontram presentes tanto os elementos relacionados à simbolização quanto à interação. A leitura é uma forma de inserção do homem no mundo, pois a partir do momento que ele lê tem a possibilidade de perceber a si e ao outro, pode compreender o mundo na sua complexidade e tomar consciência da importância de sua ação na sociedade. Assim, a leitura apresenta-se como forma de interação, de socialização, como meio de tornar o homem mais livre e consciente.

De acordo com Kleiman (1989), o ato de ler é concebido como um processo interativo entre autor e leitor, mediado pelo texto, pressupõe conhecimentos (de mundo, de língua) por parte do leitor, para que haja compreensão e apreensão da mensagem, a fim de que ele realize um trabalho ativo de construção de significado. Ler é, antes de tudo, compreender e negociar sentidos. Para uma leitura efetiva, o leitor precisa ativar conhecimentos prévios (lingüísticos, textuais, enciclopédicos).

Os PCN (1988) sugerem um ensino da língua portuguesa apoiado nos diferentes gêneros textuais, que, segundo Marcuschi (2003, p. 19), são "formas verbais de ação social relativamente estáveis realizadas em textos situados em comunidades de práticas sociais e em domínios discursivos específicos". Pactuando com as idéias de Schneuwly \& Dolz (2004), consideramos o gênero como uma estratégia de mediação entre as práticas sociais e os objetos escolares. Por meio dos diferentes gêneros textuais, é possível desenvolver a habilidade leitora do aluno, facultando-lhe o direito de construir sentidos para o texto, numa atitude ativa e relacionada com o meio em que está inserido.

Recorrendo mais uma vez a Schneuwly \& Dolz (2004), eles propõem que se organize, primeiramente, um modelo didático de gênero, ou seja, um levantamento de suas características, a fim de chegar às dimensões ensináveis. Nesse sentido, a partir dos gêneros é possível articular uma série de atividades que levem os alunos a lerem o texto, partindo da verificação do conhecimento prévio sobre o gênero, além de

\begin{tabular}{|l|l|l|l|l|l|}
\hline Interfaces da Educ. & Paranaíba & v. 2 & n. 5 & p.46-57 & 2011 \\
\hline
\end{tabular}


proporcionar o conhecimento da situação de produção, a organização textual, os elementos lingüísticos e os não lingüísticos, promovendo nos alunos não só a competência leitora, como também o desenvolvimento das capacidades da linguagem que lhes permitirão agir nas variadas situações de comunicação de que participem.

No processo de ensino-aprendizagem da leitura, o professor, como mediador, precisa explicitar estratégias de leitura (Solé, 1988) que levem o aluno a ativar o conhecimento prévio, a distinguir o essencial do que é pouco relevante no texto e, sobretudo, explicitar o objetivo da leitura. Além disso, faz-se necessário pensar em estratégias que possibilitem ao discente criar expectativas e fazer previsões daquilo que está(rá) lendo. Pensar em estratégias de leitura é levar o leitor a interiorizar o processo do ato de ler e socializá-lo com seus pares, suscitando no aluno as diversas utilidades/finalidades da leitura e proporcionar a ele recursos naturais para que se transforme em um leitor crítico.

\section{Procedimentos Metodológicos e Cenário da pesquisa}

A preocupação em verificar as atividades de leitura usadas na formação de um professor reflexivo, considerando as atividades de leitura que ocorrem no processo de ensino-aprendizagem, definiu o nosso percurso para coletar, analisar e interpretar os dados obtidos por meio de um questionário em confronto com o referencial teórico e com a análise dos Projetos Pedagógicos dos Cursos de Letras, objetos de pesquisa deste trabalho.

Procuramos refletir sobre o discurso apresentado pelos informantes desta pesquisa, analisado por meio das respostas ao questionário - com quatro questões abertas relativas à formação acadêmica, exercício profissional e em relação às atividades de leitura desenvolvidas em aula. $\mathrm{O}$ questionário foi enviado, por email, para professores de língua portuguesa, prática de ensino de língua materna e de didática da língua portuguesa de três IES no Estado de São Paulo: duas na região do grande $\mathrm{ABC}-$ IES A e IES B e uma no interior, IES $\mathrm{C}^{1}$.

Na IES A, o processo para coleta de dados foi muito complexo. O primeiro contato foi em outubro de 2006, mas somente em junho de 2007 foi possível estabelecer uma comunicação direta com sete professores envolvidos no curso de Letras, dos quais quatro nos enviaram resposta. A Instituição vivenciou cinquenta e cinco dias de greve, problemas administrativos e reestruturação pedagógica, que dificultaram a devolutiva do questionário.

Durante o mês de fevereiro de 2007, na IES B, foram convidados a responder ao questionário seis professores que ministravam uma das disciplinas mencionadas. Somente três devolveram o questionário, fato que ocorreu na semana seguinte.

Conversamos pessoalmente com oito docentes da IES C e, posteriormente, foram enviadas as perguntas. Dentre eles, cinco deram uma devolutiva, dois justificaram a não entrega; um alegando acúmulo de trabalho e outro, problemas pessoais.

Foram eleitos aleatoriamente três informantes de cada uma das IES. Evidentemente esta pesquisa não traduz com exatidão o trabalho que se realiza com as atividades de leitura na formação inicial do professor de língua portuguesa. Nem tínhamos essa pretensão. Mas, sem dúvida, esta pesquisa aponta para alguns indícios de

\footnotetext{
${ }^{1}$ Por questão de ordem ética, optamos por omitir os nomes das IES, que serão designadas como A, B e C, conforme apontamos no texto.
}

\begin{tabular}{|l|l|l|l|l|l|}
\hline Interfaces da Educ. & Paranaíba & v. 2 & n. 5 & p.46-57 & 2011 \\
\hline
\end{tabular}


como as atividades de leitura são realizadas (quando realizadas) na graduação em Letras.

Optamos pela pesquisa qualitativa, tendo em vista que o informante/professor é considerado um elemento ativo e determinante no processo de investigação e, ainda, pelo fato de que há um maior envolvimento entre os sujeitos da pesquisa.

Por meio dos questionários, buscamos, então, analisar o discurso dos informantes, a partir da seguinte indagação: $O$ estudante de Letras, futuro professor de língua portuguesa, tem recebido formação teórica em relação à Leitura para atuar na escola básica? E, ainda, em sua formação, tem sido levada em conta a articulação teoria e prática, gêneros textuais diversos no processo de leitura?

Pretendemos, assim, trazer à baila algumas reflexões sobre as práticas de leitura dos professores formadores, cujo papel desempenhado no curso superior se reflete na docência do professor da escola básica e, ainda, considerar as condições concretas nas quais se efetua o trabalho com a leitura na formação inicial do professor de língua portuguesa.

\section{O professor formador em cena}

A análise do questionário respondido pelos informantes nos permitiu confrontar os discursos deles com os documentos institucionais e oficiais e, a partir daí, registrar, em alguns momentos, o distanciamento entre a teoria e a prática na formação inicial de um professor reflexivo. Na verdade, a prática docente está muito distante do que informa os documentos institucionais e o que se determina nos oficiais. Constatamos, ainda, algumas (in)coerências nas práticas pedagógicas dos professores formadores em relação às atividades de leitura.

$\mathrm{Na}$ Introdução das Diretrizes Curriculares do Curso de Letras (CNE/CES 492/2001), evidencia-se a função social e transformadora da Universidade, em especial, na formação inicial do professor. Este documento reforça, ainda, a necessidade de que sejam desenvolvidas habilidades e competências que levem o estudante a intervir ativamente na sociedade.

Pactuando com Silva (2005), a atividade de leitura não pode se resumir em atividades livrescas, longe das expectativas e do conhecimento prévio do aluno, distante de tornar o conhecimento (o desejo por este e sua descoberta) algo significativo no cotidiano do ser humano. A Universidade, face ao compromisso que tem com a sociedade, precisa criar uma política de leitura para a formação inicial do professor de português, a fim de que este se torne, de fato, um leitor e não simplesmente um ledor.

É a ação do professor-formador que conduzirá todo esse processo, que vislumbrará caminhos a serem percorridos pelo futuro docente de língua portuguesa, desenvolvendo neste competências necessárias para que ele possa ter em seu projeto profissional o compromisso de despertar o prazer e o envolvimento de seu discente com $\mathrm{o}$ ato de leitura.

\section{Com a palavra, o informante formador, o sujeito da pesquisa}

\section{Quanto à sua formação e ao exercício profissional}

Foram sujeitos desta pesquisa nove professores universitários, dos quais apenas um não tem formação inicial no curso de Letras. Sua formação é em Jornalismo. Quanto

\begin{tabular}{|l|l|l|l|l|l|}
\hline Interfaces da Educ. & Paranaíba & v. 2 & n. 5 & p.46-57 & 2011 \\
\hline
\end{tabular}


à pós-graduação, um possui pós-doutorado na área de Letras, quatro são doutores, um é mestre e os demais possuem especialização na área de Língua Portuguesa. Na IES C, por ser Instituição pública e exigir o ingresso por meio de concurso com o título de doutor, os três informantes são doutores, com dedicação exclusiva, o que já torna o trabalho deles diferenciado em relação aos outros informantes, que trabalham entre quatro e doze horas semanais na IES. Na IES A apenas um informante é doutor e na IES B todos são especialistas.

Um ponto que nos chama a atenção quanto à formação e ao exercício profissional é a atuação na escola básica desses informantes das IES. Dois informantes da IES C não têm experiência no Ensino Fundamental e Médio. Aquele que vivenciou a docência na escola básica mostra-se mais sensível à necessidade de se trazer para a sala de aula suas experiências, evidenciando para os futuros professores a importância de se conciliar teoria e prática, o que torna o processo de ensino-aprendizagem significativo para os sujeitos.

A todo momento, verificamos no discurso do informante a preocupação em chamar a atenção para a relação que há entre trabalhar com os alunos do curso superior, em especial com os da Licenciatura, e o exercício da docência que esses futuros professores terão no Ensino Fundamental e Médio. É exatamente essa prática que o curso superior necessita, para que não haja um distanciamento entre esses dois níveis de aprendizagem. Ao levar para sala de aula experiências vivenciadas na escola básica, leituras de diferentes realidades em diversas perspectivas, desperta-se nos alunos o interesse em colocar-se (ou imaginar-se) diante de determinadas situações em sala de aula que precisarão ser resolvidas. Para isso, requer mudança de ação e a apreensão de conteúdos para que sejam desenvolvidas determinadas habilidades, a fim de que ele possa exercer competentemente a docência e levar seus alunos à transformação tão almejada pela Educação.

Os informantes da IES A têm condutas diferentes entre si em relação a esse ponto. Um deles, ao se referir sobre a relação que faz entre a formação do futuro professor e a prática docente, afirma: "Em geral, são assuntos relacionados à indisciplina ou às dificuldades de aprendizagem dos alunos". Outro responde: "Com mais freqüência, uma vez que os alunos na grande maioria são professores da escola básica e trazem para a sala de aula os anseios e dúvidas da profissão”. No entanto, há um informante que não exercita tal prática, que é tão relevante no cotidiano da sala de aula do curso de formação inicial.

Os informantes da IES B apresentam um discurso contraditório, uma vez que, neste primeiro momento do questionário, dizem não ser comum introduzirem em sua prática docente a relação entre sala de aula do curso superior com a escola básica. No entanto, como veremos adiante, levam os alunos a refletir sobre a prática de leitura na futura prática docente. Um deles alerta os futuros professores para o fato de que enfrentarão vários problemas no Ensino Fundamental e Médio. Entre eles, "o problema de indisciplina dos alunos aliada à ausência da família na escola.". Os outros informantes afirmam não terem contatos com essa realidade. Um deles ressalta apenas o fato de que, "às vezes, em determinada turma, existem alunos que já atuam como docentes e estes relatam algumas situações por que passam no processo de ensino e aprendizagem, como professores", mas não aprofunda o assunto ou abre espaço para discussão.

\begin{tabular}{|l|l|l|c|c|c|}
\hline Interfaces da Educ. & Paranaíba & v. 2 & n. 5 & p.46-57 & 2011 \\
\hline
\end{tabular} 


\title{
A prática pedagógica e o trabalho com a leitura
}

O primeiro ponto a se considerar quanto à prática pedagógica é que as três IES apresentam como objetivo primeiro, em seus PPCs, a formação de professores de língua portuguesa e respectiva literatura para a escola básica. Tendo em vista essa consideração, seria pressuposto que os cursos de Letras das IES destinassem um espaço para atividades de leitura que visassem ao trabalho na escola básica.

Atividades com a leitura na sala de aula, hoje, possibilitam ao professor propor os mais variados exercícios, levando os alunos a ter contatos com os diferentes gêneros textuais. Trabalhar com a leitura, a partir dos gêneros textuais, abre um leque de opções que levam o aluno a descobrir o mundo, a deslocar-se para espaços inimagináveis e perceber detalhes que estão presentes em seu dia-a-dia.

O sucesso do processo ensino-aprendizagem depende da intencionalidade, da contextualização, da valorização do conhecimento prévio do aluno e da adoção de estratégias que atendam adequadamente às exigências do contexto atual dos atores nele envolvidos.

Trabalhar a leitura no curso de formação inicial de professores exige a articulação da competência textual, linguística, temática e pragmática. Só assim, o futuro professor levara seus alunos a exercitar a leitura como uma forma crítica de entender o mundo, criando sentido para o texto lido. Sem dúvida, como aponta Rösing (2003, p. 63),

Pressupondo que o texto pode designar uma unidade semântica expressa em diferentes linguagens, o texto escrito, no âmbito das sociedades letradas, reveste-se de importância singular. É objeto da leitura, local da prática de interação entre autor e leitor na busca da construção do significado, ressalvadas as peculiaridades de cada pólo envolvido e as características do próprio texto.

É necessário (re)pensar o "como" trabalhar o texto na formação inicial do professor de língua portuguesa, para que se tenha um professor competente no exercício de suas funções docentes. Oportunizar os diferentes gêneros textuais é condição "sine qua non" para que os alunos vejam o texto como um elemento integrador dele (aluno) na comunidade da qual faz parte.

Kaufman \& Rodríguez (1995, p. 45) afirmam que

\begin{abstract}
a tarefa de selecionar materiais de leitura para os alunos é, em todos os níveis e modalidades da educação, uma das tarefas mais árduas que o informante tem de assumir em sua atividade pedagógica. Selecionar implica avaliar e, portanto, acatar o caráter de objeto passível de avaliação de todos os materiais de leitura: os objetos a selecionar passam a estar informantes a juízos racionais em função de diversos critérios a determinar.
\end{abstract}

Pelas palavras das autoras, percebemos a necessidade de se desenvolver essa habilidade nos futuros professores de língua portuguesa. É responsabilidade do professor formador esse trabalho. Cabe a ele iniciar a prática, levando seu aluno a vislumbrar as possíveis estratégias de leitura e de sua avaliação no exercício da docência. O professor formador não pode ser omisso à tarefa pedagógica.

No tocante às atividades de leitura que realizam na sala de aula, há uma diversidade muito grande na prática adotada pelos informantes das três IES.

\begin{tabular}{|l|l|l|l|l|l|}
\hline Interfaces da Educ. & Paranaíba & v. 2 & n. 5 & p.46-57 & 2011 \\
\hline
\end{tabular}


Embora somente um dos informantes do curso de Letras do IES C ministre disciplinas que estejam voltadas especificamente para a leitura e gêneros textuais, observa-se pelas respostas aos questionários que, também, outro informante procura promover a interação entre os alunos, por meio da leitura de textos de variados gêneros, visando à formação e à preparação de um profissional para a escola básica, com "resultados bastante satisfatórios", como ele afirma.

O informante cujo trabalho é específico com a leitura e com os gêneros textuais diz: "Solicito aos alunos a leitura e o fichamento dos textos teóricos, para a discussão dos conceitos em sala de aula". E completa:

\begin{abstract}
Procuro trabalhar o conteúdo do programa com base em textos teóricos da área de Lingüística e de Língua Portuguesa. Em seguida à discussão de um texto teórico, há a proposta de produção de texto. Em geral, o aluno é colocado em situação de reflexão sobre a relação entre o texto teórico, a formação acadêmica e a prática social da profissão. As propostas de produção de texto apresentam, com freqüência, mais de um texto de apoio, no(s) qual(is) o aluno deve se fundar para construir seu lugar de reflexão. Desse modo, acredito, trabalho com determinada noção de autoria em textos acadêmicos, segundo a qual o aluno deve reconhecer que é ele que "orquestra" diferentes "vozes" para a produção textual (escrita ou falada). De uma perspectiva dos estudos sobre gênero, procuro mostrar que a constituição de um texto se dá muito mais por características que são intergenéricas do que por aquelas que são tomadas como exclusivas de determinado texto.
\end{abstract}

O trabalho desenvolvido pelo informante desencadeia uma série de observações. Ele demonstra a preocupação em associar teoria e prática, o que sinaliza para o atendimento de algo em que acreditamos: não é possível formar competentemente um profissional sem que ele consiga articular teoria e prática, além de conhecer o todo do assunto tratado e saber organizá-lo em partes, com um objetivo determinado.

A manifestação deste informante ainda evidencia o exercício constante para que o aluno reconheça as diferentes vozes presentes em um texto e saiba utilizá-las nas suas atividades de leitura e na escrita, sem perder de vista a presença de traços de sua autoria no texto produzido. Na verdade, exercita-se o diálogo intertextual que desperta no aluno a criticidade, o pensar, o refletir, o associar diferentes discursos, em diferentes perspectivas, a partir de um mesmo evento.

O terceiro informante não tem a preocupação em trabalhar com leitura em suas aulas. $\mathrm{Na}$ verdade, seu trabalho volta-se para a "pesquisa linguística", sem fazer qualquer referência à formação do estudante para o desempenho das atividades em sala de aula enquanto docente. Na verdade, em nenhum momento, este informante evidencia seu olhar para a formação do professor enquanto um leitor e formador de leitores na escola básica. Privilegia a formação de um pesquisador. Segundo ele, "não realizo trabalho que esteja voltado para interação "com" e "dos" alunos, no tocante à leitura e aos gêneros textuais, tampouco estratégias que visem à formação inicial do informante de língua portuguesa para a escola básica".

Na IES A, um informante explicita, em relação ao trabalho com a leitura na sala de aula do curso superior:

Por ter sido minha primeira experiência, não foi muito fácil no início. Precisei de algumas aulas para me adaptar à Instituição, aos alunos e ao

\begin{tabular}{|l|l|l|l|l|l|}
\hline Interfaces da Educ. & Paranaíba & v. 2 & n. 5 & p.46-57 & 2011 \\
\hline
\end{tabular}


próprio curso. Após esse período, priorizei em meu planejamento questões relacionadas ao ensino da língua Inglesa e da Língua Portuguesa, seguindo as diretrizes dos PCNs.

Importante ressaltar que ele tem a preocupação de preparar os futuros informantes a trabalhar com as propostas dos PCNs; leva as diretrizes desse documento para o curso de formação inicial, tornando-o familiar aos alunos. Neste sentido, este informante mostra-se preocupado em proporcionar uma formação inicial que leve o aluno à sua autonomia, a deparar-se com diferentes documentos que norteiam o ensino da língua, para que, a partir deles, seu aluno construa uma identidade enquanto docente.

Da fala do outro informante, apreende-se a prática de um trabalho que vise à formação de alunos reflexivos, a qual seja capaz de levar o aluno a construir conhecimentos, vislumbrar os caminhos por que pretende trilhar no magistério. Ele enfatiza um trabalho marcado por "Leituras, reflexões, exercícios e textos que os levem a pensar sobre possíveis estratégias para sua prática docente.”.

Em virtude da maior experiência na Educação, o terceiro informante pôde traçar reflexão sobre o trabalho que desenvolve durante o exercício da prática docente. Segundo ele,

\begin{abstract}
ao longo do tempo que lecionei e leciono, percebo que há uma dinâmica interessante entre a questão teórica e a prática, sendo docente de didática procuro criar situações de aprendizagem onde existe a possibilidade de fazer a relação teoria e prática e interagir com os alunos através de um currículo dinâmico, dialógico em que a leitura seja o elemento interdisciplinar que norteie o curso.
\end{abstract}

Dessa fala, apreendemos que sua prática pedagógica cria condições concretas e efetivas para a realização dos propósitos que se anunciam no curso de Letras da IES A: formar professores para a escola básica, oferecendo a eles a possibilidade de conviver, na realidade, com os múltiplos olhares que um professor precisa ter para seu aluno, para a escola, para o mundo.

O discurso deste informante explicita o proposto nas Diretrizes Curriculares do Curso de Letras, sobretudo nos aspectos relativos à necessidade de que sejam articuladas habilidades e competências cujo objetivo seja o desenvolvimento de atividades crítico-reflexivas durante a integralização do curso, por meio de trabalho com os diferentes saberes para uma formação inicial competente. Ele evidencia, ainda, a questão da multidisciplinaridade.

Se for destinado um momento de leitura durante essa formação, o desenvolvimento de habilidades que promovam a multidisciplinaridade será concretizado, uma vez que a leitura, entendida como uma prática social, constitui-se em uma atividade que, nas palavras de Silva (2005, p. 47),

\footnotetext{
não pode prescindir de situações vividas socialmente, no contexto da família, da escola, do trabalho, etc... Todos os seres humanos podem se transformar em leitores da palavra e dos outros códigos que expressam a cultura, mesmo porque carregam consigo o referido potencial biopsíquico (aparato sensorial + consciência que tende à compreensão dos fenômenos).
}

A leitura com fichamentos e debates, reescrita de textos, criação de "estratégias que os leitores proficientes lançam mão, tais como levantar hipóteses sobre o que o texto vai falar, verificar se tais hipóteses são confirmadas ou refutadas e construir

\begin{tabular}{|l|l|l|l|l|l|}
\hline Interfaces da Educ. & Paranaíba & v. 2 & n. 5 & p.46-57 & 2011 \\
\hline
\end{tabular}


sentido para o que foi lido" constituem algumas das atividades desenvolvidas durante as aulas que os professores formadores ministram no curso de Letras da IES A.

Quanto à IES B, em relação ao trabalho com os gêneros textuais e a leitura, os três informantes veem suas propostas como "satisfatórias e razoáveis." Um deles, em relação às estratégias de leitura, afirma que procura analisar os aspectos estruturais e temáticos de cada texto visto em aula com os alunos. Considera um trabalho árduo, pois os alunos não conseguem, na maioria das vezes, fazer inferências dos textos; limitam-se a uma leitura no plano superficial. E completa, "Insisto em colocar 'temas' para desenvolver linguagem oral". Afirma ainda que há "[...] exigência de leitura e questionamentos temáticos acerca das obras lidas".

Ele salienta: "Entendendo que a leitura constitui-se em um dos modos do homem interagir com o mundo em que está inserido, num curso de Letras, em que se formam professores de língua portuguesa, o trabalho com a leitura há de desenvolver habilidades necessárias para que este futuro docente não se limite à decodificação do texto." No entanto, não evidencia quais são as estratégias que motivam seu aluno a atingir este objetivo.

O segundo informante se atém à seguinte fala:

Sempre chamo a atenção dos alunos para a questão da leitura no ensino médio e no fundamental. Digo a eles que é preciso muito cuidado na escolha do texto e nos procedimentos a serem adotados.

E não faz quaisquer outras considerações. Não menciona estratégias que utiliza para levar o futuro professor a esta reflexão.

"Nunca chamar para ler um texto oralmente sem fazer leitura silenciosa. Evitar a leitura de trechos longos e passar para o colega próximo" são as orientações que o terceiro informante passa para seus alunos. Percebe-se pelo seu discurso que ele entende a leitura como um processo mediado pela compreensão oral. Não entra nos aspectos cognitivos necessários ao ler um texto. Não considera o fato de que a leitura é um processo no qual o leitor adapta determinadas estratégias, dependendo dos propósitos que objetiva.

O terceiro informante diz: "não entro nesse assunto", sem fazer quaisquer outras considerações, ainda que ele trabalhe, também, com a disciplina "literatura portuguesa", cujo objeto de estudo, no nosso entender, é o texto e sua leitura.

\section{Considerações Finais}

Uma concepção esclarecedora sobre os objetivos que pretendem a formação inicial do professor de língua portuguesa no tocante ao trabalho com a leitura dos diferentes gêneros textuais é indispensável a qualquer IES.

Pode-se constatar que os informantes, ao serem questionados sobre o trabalho com a leitura no curso superior, não fizeram referências a uma base teórica, a um estudo que sustentasse uma perspectiva do desenvolvimento da habilidade, tampouco sobre uma teoria sobre os gêneros textuais. Os documentos institucionais e os oficiais, além dos diversos estudos sobre a formação inicial do professor de língua portuguesa, apontam a necessidade de se conciliar teoria e prática. E, a princípio, isso tem fícado apenas no papel. A prática no curso superior tem se mostrado bastante distante do ideal, conforme pudemos observar no discurso apresentado pelos professores. Não adianta

\begin{tabular}{|l|l|l|l|l|l|}
\hline Interfaces da Educ. & Paranaíba & v. 2 & n. 5 & p.46-57 & 2011 \\
\hline
\end{tabular}


reclamar que os alunos não sabem ler se os nossos professores não criam práticas educativas e estratégias de leitura para esse fim, ou pior ainda, na maioria das vezes, não estão preparados para exercitar a leitura.

Há necessidade de se repensar no trabalho com a leitura que se realiza no curso de Letras. Como vimos, as Propostas das Diretrizes do Curso de Letras, por exemplo, oferecem oportunidade para a elaboração de um currículo flexível, que favoreça os estudos da língua fundamentados numa ação social, articulando teoria e prática. No entanto, para que isso se efetive, é necessário que os professores formadores conheçam o documento e/ou coloquem-no em prática durante suas aulas.

É preciso que seja criado na Instituição Escola um espaço para o trabalho efetivo com uma leitura significativa, o qual seja capaz de construir sentidos para os sujeitos do processo de ensino e aprendizagem. Mas o objetivo só será alcançado quando houver uma mudança permeada por questionamento de conceitos enraizados, de parâmetros inflexíveis que, infelizmente, ainda se fazem presentes na nossa escola.

Estabelecer uma relação dialógica, na sala de aula do curso superior, entre os pares e entre esses e a sociedade, a fim de que a escola seja um lugar para a (re)construção crítica e consciente do conhecimento, e a partir daí, estabelecer vínculos com a educação básica, faz-se necessário e urgente. A universidade não pode ser um fim em si mesma. Os sujeitos envolvidos no processo de formação inicial terão a chance de perceber o sentido do aprender, do fazer, do "para que" e de "como ensinar", quando estiverem conscientes de sua função social. O diálogo entre Universidade e escola básica e a conscientização dos professores formadores deste fato abrem oportunidade para ouvir expectativas, conhecer as representações sobre a língua, a escrita, a leitura e sobre a própria didática na sala de aula, elementos fundamentais para a construção da identidade do professor como profissional.

O futuro professor que trabalhará com a leitura precisa ser preparado - na teoria e na prática - para projetar e realizar uma pedagogia diferenciada, criando estratégias múltiplas para que se possa ler um texto, e refletir sobre as possibilidades de exercitar a leitura junto a seus alunos. Elas se constituem em formas de inventividade didática e organizacional, levando o aluno ao auto-conhecimento. Não se pode perder de vista que o processo educativo visa a uma transformação no ser humano, por meio da socialização do conhecimento, despertando o senso crítico em cada cidadão que participa do ensino e aprendizagem. Não se forma cidadão crítico se não houver comprometimento, consciência e constância na prática docente que se realiza.

Mais do que reestruturar os programas, repensar as estratégias de leitura e interação Universidade/Escola Básica, é preciso que os professores formadores tenham uma mudança de postura face ao trabalho com a leitura no curso superior, conscientes de sua responsabilidade com a sociedade. Enquanto o professor formador não dimensionar o poder dos efeitos das estratégias que prescrevem as leituras que realiza em suas aulas, para a formação de um professor leitor competente, o ato de ler na escola não atingirá seu objetivo maior, ou seja, ler para transformar, para refletir, para questionar, para (re)construir sentidos para a vida.

Acreditamos que essa mudança de postura do professor formador seja um possível caminho que possibilite o futuro professor a vislumbar que tipo de estratégias precisam ser exercitadas no Ensino Fundamental e Médio e em que gradação são estabelecidas para o desenvolvimento da competência leitora de seus alunos. Esses são pontos a serem revistos pelos cursos de Letras, a fim de que cumpra efetivamente sua missão, ou seja, formar professores leitores, competentes e compromissados com a

\begin{tabular}{|l|l|l|l|l|l|}
\hline Interfaces da Educ. & Paranaíba & v. 2 & n. 5 & p.46-57 & 2011 \\
\hline
\end{tabular}


escola básica de acordo com as exigências da sociedade em que estão inseridos. Mais que isso: professores conscientes da sua função social para a formação de cidadãos críticos, que saibam ler o texto-mundo.

\section{Referências}

GERALDI, J. W. (org.). O texto na sala de aula. 3. ed. São Paulo: Ática, 2001. . Portos de Passagem. São Paulo: Martins Fontes, 2002.

_. Linguagem e Ensino: exercício de militância e divulgação. Campinas: Mercado de Letras, 1999.

KAUFMAN, A. M. \& RODRÍGUEZ, M. H. Escola, leitura e produção de textos. Porto Alegre: Artmed Editora, 1995

KLEIMAN, A. Texto e leitor: aspectos cognitivos da leitura. 2. ed. São Paulo: Pontes, 1989.

. Leitura: ensino e pesquisa. 2. ed. Campinas: Pontes, 2001.

MARCUSCHI, L. A. "Gênero textual: definição e funcionalidade. In: DIONISIO, A. P., MACHADO, A.R. \& BEZERRA, M A. Gêneros textuais e ensino. Rio de Janeiro: Lucerna, 2003.

PERRENOUD, P. Construir competências desde a escola. Trad. Bruno Charles Magno. Porto Alegre: Artmed, 1999.

PIMENTA, S. G. \& ANASTASIOU, L. G. C. Docência no ensino superior. São Paulo: Cortez, 2002.

PIMENTA, S. G. (Org.) Didática e formação de professores: percursos e perspectivas no Brasil e em Portugal. 3. ed. São Paulo: Cortez, 2000.

PIMENTEL, M. G. O professor em construção. Campinas: Papirus, 1993.

ROSING, T. M. K. A formação do professor e a questão da leitura. Passo Fundo: Editora da UFP, 2003.

SCHNEUWLY, B. \& DOLZ, J. Gêneros Orais e Escritos na escola. Trad. Roxane Rojo \& Glais S. Cordeiro. Campinas: Mercado de Letras, 2004.

SILVA, E. T. A produção da leitura na escola: pesquisa x propostas. São Paulo: Ática, 1995.

. Conferências sobre leitura. 2. ed. Campinas: Autores Associados, 2005.

Elementos de pedagogia da leitura. 3. ed. São Paulo: Martins Fontes, 2005.

SOLÉ, I. Estratégias de leitura. Trad. Claudia Schilling. Porto Alegre: Artmed, 1998.

VEIGA, I. P. (Org.). Projeto Político-Pedagógico da Escola: uma construção possível. 22. ed. Campinas: Papirus Editora, 1998.

\section{Documentos oficiais}

BRASIL, Lei de Diretrizes e Bases, 1996

BRASIL, Propostas Curriculares do Curso de Letras

BRASIL Parecer 9/2001 